\title{
Research on Means Analysis and Its Regulations in Financial Engineering
}

\author{
Xiao Luo \\ School of Information Management \& Engineering, Shanghai University of Finance and Economics, Shanghai, \\ 200433
}

Keywords: Financial engineering, Financial means, Financial regulations

\begin{abstract}
This paper is divided into two parts. The first part is to talk about the author's personal views on financial engineering through the analysis of examples as well as the direction of financial engineering front. The first half demonstrates the financial engineering can replace the risk of its own, leaving behind their own favorable risks with both profit and hedge to a certain extent compatible compared to traditional finance. The second half is about the micro level risk aversion and macro level financial market supervision direction from the perspective of financial law direction.
\end{abstract}

\section{Introduction of Financial Engineering}

The term "financial engineering" was first proposed by J.D.Finnerty in 1988. Financial engineering is based on financial derivatives, including futures, options, hedging and so on. Its market has grown to the size of hundreds of millions of dollars. The pricing of derivatives depends on the price of traded goods or financial assets. The development of option theory lays a scientific theoretical foundation for the extensive application of financial derivatives. Although financial engineering is developing rapidly, there is no uniform definition so far. Finnerty believes that financial engineering is the design, development, development and implementation of financial innovation tools and processes, used to creatively solve financial problems. Financial engineering requires people to make full use of scientific and technological achievements to innovate the original means, so as to reduce transaction costs, and provide more convenient and efficient

Financial services. In dealing with some typical problems, the establishment of processing module type, and can be used as products for sale; at the same time, to solve the problem for different problems and put forward the distinctive way of some complex problems, it is necessary to emphasize the role of experts in financial field, and should be widely combined with other experts in various fields such as company accountants, tax accountants, lawyers and lawyers and other securities company, with the thought of system engineering to solve the problem. On the whole, the innovation of financial engineering is important.

\section{Arbitrage Concept and Its Applications}

Arbitrage Concept Summary. In the teacher's class, the teacher mainly introduced the arbitrage idea and its corresponding arbitrage free pricing model. By acting simultaneously in multiple markets, you can earn a risk-free profit without paying the cost. The concept that is closely related to arbitrage is arbitrage opportunity, that is, the condition of arbitrage. Arbitrage opportunities can be divided into two categories: the first arbitrage opportunity and the second arbitrage opportunity.

The so-called "first arbitrage opportunity" means that there is such a way of investment, its investment is zero (that is, no investment), the income is greater than or equal to zero, and at least in some of the results, the income is greater than zero. Second arbitrage refers to the existence of such investment, the investment is less than zero (that is, not only do not have any investment, but also by short selling also received a certain income), income is greater than or equal to zero, the worst case 
return to zero. The distinction between the two arbitrage opportunities is given by the academic community for the convenience of the analysis, and its essence is the same: there is an opportunity to profit without paying any cost.

Arbitrage Case. The so-called foreign exchange broker, is to help customers complete foreign exchange transactions service providers, commonly known as foreign exchange platform, known as foreign exchange broker. Open an account at a foreign exchange broker (broker), and you can speculate on foreign exchange like stocks. In other words, customers can buy the pound, the future is going up or down, judging the trend of the euro can make a profit. The broker's approach to the deal is different. The most conservative thing is that all the customer orders are thrown to the bank, and there is no essential difference between the Forex platform and the online foreign exchange trading page. Foreign exchange platform collects fees as a source of profit.

With the development of the industry, we found that Chinese customers in the foreign exchange account trading results are often at a loss or warehouse explosion. So brokers use "market making" (the real market is a formal way of providing liquidity, not betting on such fraudulent practices) In name, it's a gamble.

Gambling, as the name suggests. If a customer buys one hand EURUSD through a foreign exchange platform A, the order does not go to the bank, but only on the server of the other party. Because the customer loss prediction of iron sinks into the $\$ 10000$ warehouse explosion, so if gold generally a few hundred. In the whole process, if you earn fees, from gold to warehouse explosion, procedures fee can earn $\$ 100$. But if the list is not connected to the bank, but only made a record to the user's surface mounted, then the 10000 dollars into the gold, almost all of the platform profits. In fact, nothing happened, the customer gave the company 10000 dollars, and a few days later, the company sent hundreds of dollars to the customer, and the customer's money became the profit of the iron remittance. If some customers are particularly strong, or luck is particularly good, make a lot of money. Generally, there are two kinds of circumstances, one is paid from other customers and the other is paid to him. The other is suddenly disappearing. The latter is in the majority.

The bet is called "A B Book warehouse""'. The so-called A Book is received by the bank, if found to have a particularly fierce team, then pick up A Book earn commission fees. The vast majority of customers, is connected to the B Book, also is to bet, the last penny drained the customer. Today, China's so-called "foreign exchange industry", the vast majority of platform companies do B Book, commonly known as "black platform"'". And the competition in this industry is the scramble for lambs by the black platform.

The idea is that iron sinks hit, if the customer more money to do so, he will eventually lose out (ordinary investors to invest in foreign exchange is certainly lose everything, this is regarded as the basic industry of iron). If you use the gift money to attract customers into the gold, you can build a lot of advantages, but in fact do not have to spend a penny. Because of this so-called transaction gift, but is a number of trading software only, customers will be lost, so iron sinks nothing to pay, in vain to obtain a large number of customers.

In fact, as soon as the iron sinks reached a huge amount of big customers, the volume of transactions before the iron sinks fell more than the industry leader. But unlike forecasts, retail investors are not losing as much as they always do. There are a large number of customers do not know why, suddenly full of profit. So in the end is bound to be unfulfilled. The iron remittance is difficult, the signal is that iron sinks to recover $100 \%$ gold gifts. The cashing pressure at the time of remittance is not less than 100 million dollars. Iron sinks are difficult to escape the fate of collapse.

\section{Establishment of Regulating Legal System of Financial Derivatives}

Supervision Difficulties of Financial Derivatives Market. First of all, compared with other financial markets, the transparency of financial derivatives market is low, and the ordinary regulatory rules are difficult to play an effective role. The structure design of the financial derivatives, pricing model, risk assessment is more complicated, even in the financial professionals in only a few known as the "rocket scientist" financial engineers to understand its structure, but ordinary investors on the 
financial derivatives trading and risk solutions is very limited, therefore, compared with other financial markets. The financial derivatives market transparency is low, risk identification and control difficult.

Secondly, to some extent, financial derivatives are designed to avoid the current legal system of financial supervision and reduce the cost of supervision of financial institutions. Most of the financial derivatives business belongs to off balance sheet business, and has long been outside the jurisdiction of the securities regulatory, accounting regulations, bank regulations and other financial regulatory laws. Therefore, it is very difficult to implement effective supervision of the financial derivatives market under the current financial supervision system. And a large number of OTC derivatives trading, which makes the current financial derivatives regulatory system stretched.

Third, the widespread application of financial derivatives has changed the traditional corporate nature and market trading rules, and the traditional way of distinguishing financial supervision from different industries has been ineffective. In the temptation of huge profits, many traditional energy companies or manufacturing companies have started to carry out the huge financial derivatives business with their good credit, even rely on high profits on its financial sector access to make up for the loss of the traditional industry, the disclosure of financial report in various economic indicators are very good; on the other hand, the financial derivatives financial instruments also provide superior performance for manipulation of the company's financial statements. Through derivatives, companies can be pre profit and after use, can carry out a sheet business to adjust the financial statements, the indicators have reached or even exceeded the public expectations, in order to maintain its position in the capital market.

Supervision Models of Financial Derivatives Market. The institutional supervision model is a more traditional mode of financial supervision. According to the different characteristics of industry and financial institutions are regulated financial supervision form of financial market participants, financial institutions and other relevant agencies arrange different supervision system respectively, it is generally long regulatory specific application structure. The supervision of the financial derivatives market is based on the classification of its basic products, and carries out different supervision on the financial institutions engaging in different types of financial derivatives. Its advantage is to clear the regulatory authority and scope of responsibility of various regulatory agencies, to avoid the conflict of responsibilities of different regulatory agencies. At the same time, the supervision, coordination and cooperation of multiple financial regulators can promote the competition in the financial market supervision, avoid bureaucracy, supervise monopoly and abuse of rights, and improve the efficiency of financial supervision. But at the same time, the financial derivatives market is trading fast, the scale of capital transfer is large, and the risk transfer is very fast. The effect of the regular collaborative problem solving is limited. In this case, still follow the traditional financial institutions form, category of institutional supervision supervision model has been difficult to effectively manage the derivatives market, therefore, the transition of functional supervision mode played by the traditional mode of regulation of institutions to pay attention to the function of financial markets has become an inevitable trend.

Functional supervision mode refers to the form of financial supervision that supervises and manages the financial market according to the types of financial institutions' business activities and the basic economic functions they play. It can be built on the basis of a single regulatory structure, and can also use a multi-line regulatory structure to build its regulatory system. The utility model has the advantages to achieve the same financial functions of financial institutions and financial services to the same degree of regulation, which is conducive to the specific legislative interpretation and application, also created equal conditions for competitors, make financial institutions involved in the same financial business under the same degree of regulation, improve regulatory efficiency in a certain degree on. The problem is that the function of financial institutions is not immutable and unchanging, and the cost of changing regulatory methods is higher than that of institutional supervision.

Based on the unified regulation refers to the maintenance of financial security, based on the unitary supervision organization structure, to effectively determine the objective of financial 
regulation as the foundation, the implementation of multi-level unified supervision and management of the financial supervision system of financial markets, financial institutions, financial institutions and other business itself. The financial derivatives itself may involve a number of the financial sector, is a typical "financial complex", which requires the market supervision of the legal system of financial derivatives must also have the characteristics of cross market, cross industry, in order to implement effective supervision. It is difficult to separate the mixture after the regulation, for example, with the further development of financial deepening and liberalization, securities companies and insurance

The company can carry out all kinds of portfolio with new financial instruments, the risk characteristics and the bank are similar; and at the same time banks also have the same ability to adjust their risk characteristics with traditional securities company or insurance company is similar. Therefore, effective financial regulatory legal system must be designed and arranged for the nature and characteristics of "financial composition", rather than separately regulating different financial institutions or products

On the other hand, with the relaxation of financial control, the acquisition of financial institutions is more popular, and the trend of collectivization of financial institutions is becoming increasingly evident. This makes it necessary to establish and implement a unified regulatory model.

Comparative Advantage of Unified Supervision. First of all, unified supervision is conducive to strengthening the comprehensive supervision of the financial derivatives market and improving the efficiency of supervision. The financial derivatives market involves many financial fields, and the traditional supervision modes of many agencies often appear in the coordination of each other, such as regulatory vacuum, regulatory conflict or unclear regulatory responsibility. Unified supervision can effectively solve this problem. Second, the unified supervision is more concerned about the nature of the business undertaken by the financial institutions and the realization of the risk control objectives, not only the name or type of the financial institutions, but also conducive to the realization of regulatory fairness. Financial institutions engaged in the same business and market participants will receive the same degree of regulation, restriction degree rather than the same nature of the market behavior regulated system, that is always the same burden of regulators of financial supervision cost. Therefore, unified supervision is more conducive to improving the environment of financial supervision, and maintaining fair competition of financial institutions in the financial derivatives market.

\section{Conclusion}

Financial engineering is the design, development and implementation of financial innovation tools and processes, which is used to creatively solve financial problems. Even faced with the complicated and difficult cost of management, the unified supervision is the construction direction of the legal supervision system of financial derivatives.

\section{References}

[1] Prasch R, Warin T. Systemic risk and financial regulations: A theoretical perspective[J]. Journal of Banking Regulation, 2016, 17(3): 188-199.

[2] Buss A, Dumas B, Uppal R, et al. The intended and unintended consequences of financial-market regulations: A general-equilibrium analysis[J]. Journal of Monetary Economics, 2016, 81: 25-43.

[3] Pelikan P. 6 Financial regulations for minimizing economic and social crises[J]. Economic Policy and the Financial Crisis, 2014: 117.

[4] Goodhart C A E, Kashyap A K, Tsomocos D P, et al. An integrated framework for analyzing multiple financial regulations[J]. International Journal of Central Banking, 2013, 9(1): 109-143. 